\title{
Erratum zu: \\ Anwendungsgebiete neuer Werkstoffe
}

Die aktualisierte Version des Kapitels finden Sie unter https://doi.org/10.1007/978-3-662-59440-7_5 
Erratum zu: Kapitel 2 in: H. Hofmann, J. Spindler, Anwendungsgebiete neuer Werkstoffe, https://doi.org/10.1007/978-3662-59440-7

Das Wort „Katheder“ wurde zu „Katheter“ geändert. 